\title{
A historical climatology of the easterly winds in the strait of Gibraltar
}

\author{
Paula HIDALGO and David GALLEGO*
}

Departamento de Sistemas Físicos, Químicos y Naturales, Universidad Pablo de Olavide, km 1 carretera de Utrera, 41013 Sevilla, España

*Corresponding author; email: dgalpuy@upo.es

Received: September 11, 2018; accepted: May 24, 2019

\begin{abstract}
RESUMEN
En este trabajo se utilizan medidas históricas de dirección del viento tomadas a bordo de barcos de vela para definir un nuevo índice representativo de la frecuencia de los vientos de levante en el estrecho de Gibraltar, en la costa de Europa meridional. La nueva serie comienza a fines del siglo XIX y añade casi 100 años a series comparables anteriores. Se ha encontrado una gran variabilidad en los vientos de levante a escala anual y decadal a lo largo de todo el siglo XX, aunque no se han encontrado tendencias de largo plazo. Adicionalmente, en este trabajo demostramos que la variabilidad de los vientos de levante en el estrecho de Gibraltar está relacionada con la Oscilación del Atlántico Norte y con anomalías en la presión a nivel del mar sobre todo el Atlántico Norte y Europa continental.
\end{abstract}

\begin{abstract}
In this paper, we use historical wind direction observations taken aboard sailing ships to build a new index for the frequency of the easterly winds in the strait of Gibraltar, in southern Spain. The new series starts in the late 19th century, adding almost 100 years to comparable previous series. We have found large interannual and decadal fluctuations in the frequency of the easterly winds in Gibraltar along the 20th century, although no long-term trends have been revealed. We show that the changes in the frequency of the easterly winds in Gibraltar appear significantly related to the North Atlantic Oscillation and to anomalies in the sea level pressure across the North Atlantic and large areas of Europe.
\end{abstract}

Keywords: Gibraltar, historical climate, climate indices

\section{Introduction}

The strait of Gibraltar, the channel separating western Europe from the African continent (Fig. 1), is less than $20 \mathrm{~km}$ wide at its narrowest point and it possesses a very peculiar wind climatology. The orography of southern Spain and northern Morocco, characterised by abrupt mountain ranges, along with the typically stable thermal stratification of the lower troposphere in the area, channel the wind in a preferential westeast direction (Fernández, 1992). Occasionally, these winds can reach velocities close to $30 \mathrm{~m} \mathrm{~s}^{-1}$, affecting the air and sea communication between western
Europe and northern Africa. The large values of the average wind speed and the steadiness of the wind direction in this region have stimulated the installation of a large number of wind farms in southern Spain in the last decade, with more than $1300 \mathrm{MW}$ of installed power. It is also well known that the westerly winds in the strait of Gibraltar are usually related to the presence of low pressure systems near the Portuguese coast, which occasionally can reach the storm level making significant morphological changes on beaches (del Río et al., 2012). Even though the westerlies are important, among locals, the most "feared" wind 
(a) \# OBS (1800-2014)

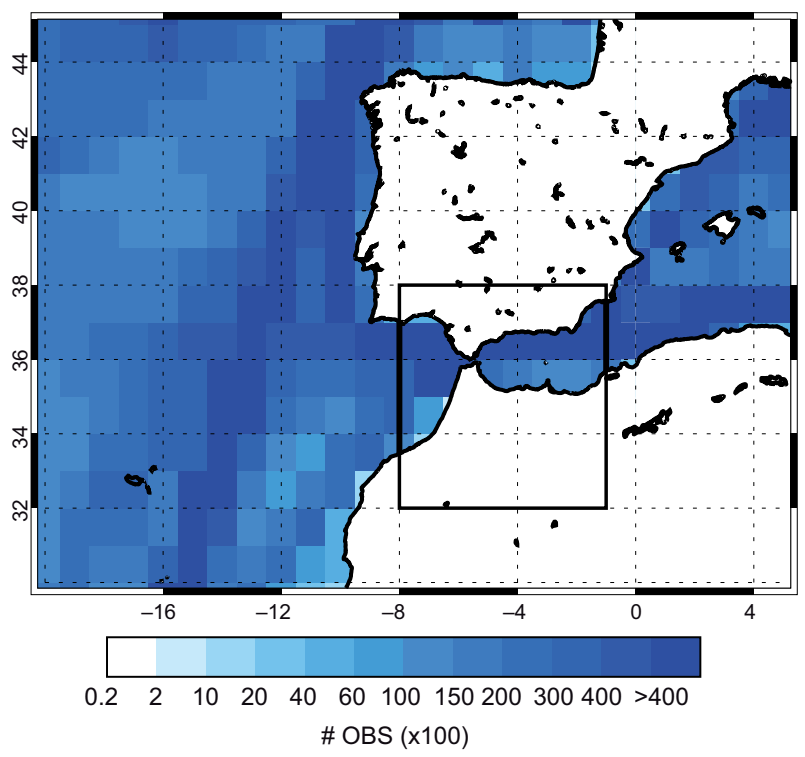

(b) \# Wind obs [8W-1W]/[32N-38N]

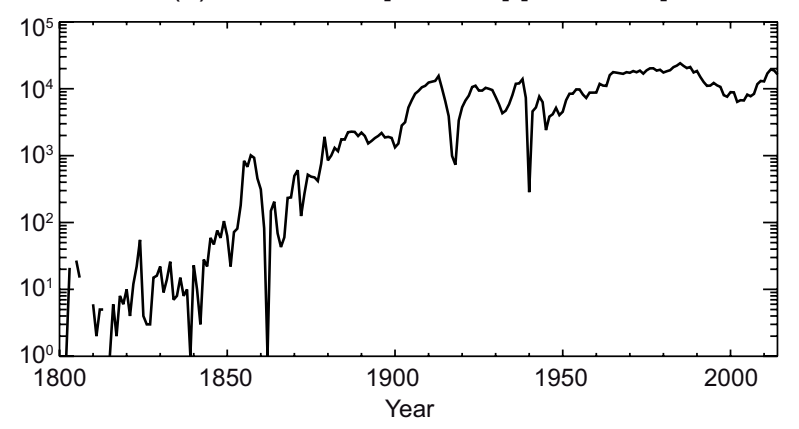

Fig. 1. (a) Number of wind direction observations in a $1^{\circ} \times 1^{\circ}$ latitude-longitude grid for the $1800-2014$ period available in ICOADS 3.0. Black rectangle indicates the area selected to compute the EDIN. (b) Time evolution of the cumulative number of wind direction observations inside the $\left(32^{\circ} \mathrm{N}-38^{\circ} \mathrm{N}, 8^{\circ} \mathrm{W}-1^{\circ} \mathrm{W}\right)$ domain.

regime in the strait of Gibraltar is related to the easterly winds ("levanters" in the following). During the summer, levanters are usually associated to extremely hot weather in southern Spain. The strength of these easterly winds is linked to the location and intensity of the Azores High (Fernández, 1992) and they can be extraordinarily persistent in the strait. Despite the interest in characterising the easterly winds in the strait of Gibraltar, beyond the generalist descriptions of these winds (Fernández, 1992), the few specific wind studies for this region are limited to short-term observation campaigns (Dorman et al., 1995) or particular case studies (Capon, 2006). This small number of studies has probably its origin in the scarcity of long and continuous wind records at daily resolution. These records started to be continuous only from the 1970s on, and only in a few observation sites on land.

During the last five years, a number of works (Barriopedro et al., 2014; Gallego et al., 2015; Ordóñez et al., 2016; Vega et al., 2018) have made use of historical wind direction observations taken aboard sailing ships to develop long-term climatologies of diverse climatic structures such as the North Atlantic Oscillation (NAO) or monsoonal circulations (García-Herrera et al., 2018). Because of its strategic location, the strait of Gibraltar has been heavily navigated since early times. Most of the ships traveling by this area took detailed wind measurements that were annotated into their logbooks. Many of these early records have survived in historical archives and, as a result of several recovery projects (García-Herrera et al., 2005; Allan et al., 2011; Wilkinson et al., 2011, among others), much of these valuable meteorological observations have been incorporated into free digital databases (Freeman et al., 2017). In this paper, we make use of these observations to build the first climatology of the easterly winds in the strait of Gibraltar starting in the late 19th century.

\section{Data and methods}

\subsection{Directional indices}

Even although it is possible to find historical meteorological observations in ships logbooks since the 17 th century, they are not always operational to build a quantitative index. Meteorological instruments (barometer, hygrometer, rain gauge, etc.) were not routinely carried aboard ships prior to the mid 20th century. And even by that time, the wind observation, probably the most important from a nautical point of view, was not usually recorded by using anemometers. In the vast majority of the cases, even after the mid 20th century, wind observations aboard ships were performed and codified using the Beaufort scale. There are methods to "translate" these semi-quantitative observations into their numerical equivalents (Prieto et al., 2005), but it is quite difficult to perform this task for long periods because of the change in the use of the language along the decades (Gallego et al., 2007). These difficulties are mostly related to the use of multiple languages, 
descriptors and modifiers to express the wind force in terms that did not necessarily follow the Beaufort's standards (Prieto et al., 2005).

For historical wind observations, only the wind direction measurement can be considered an instrumental one. Wind direction was measured with a compass in essentially the same way since early times, and this is the reason why during the last years, a number of climatic indices based on the analysis of wind direction alone have been developed. These indices have been dubbed as "directional indices" (Barriopedro et al., 2014). A directional index is usually defined as the percentage of days in a month with prevailing wind flowing from a certain direction or range of directions (García-Herrera et al., 2018), so they are a direct measure of the wind persistence. Additionally, it has been demonstrated that at monthly scales, these indices are representative of the changes in wind velocity as well (García-Herrera et al., 2018).

\subsection{Data}

For this research, we used the raw data contained in the last release (3.0) of the International Comprehensive Ocean-Atmosphere Data Set (ICOADS), which stores meteorological data taken at sea level aboard sailing ships and other marine platforms (buoys, tide gauges, etc.) for the last three centuries. At the time of writing, ICOADS data starts in 1662 and ends in 2014, holding over 456 million individual marine reports. Unfortunately, the data covering the period from 1662 up to the early 1800s are based on scattered ship voyages and, consequently, they are rather sparse. ICOADS data are rigorously quality controlled. A complete description of this database is provided in Freeman et al. (2017).

Apart from ICOADS, for calibration purposes we used data from the Spanish Meteorological Agency (AEMET). We took anemometer data from the Tarifa meteorological station in southern
Spain located at $5^{\circ} 35^{\prime} 56^{\prime \prime} \mathrm{W}, 36^{\circ} 00^{\prime} 50^{\prime \prime} \mathrm{N}$ and at 32 masl. Tarifa is in the southernmost extreme of the Iberian Peninsula and it is considered to be highly representative of the average wind regime in the strait of Gibraltar (Stepek et al., 2012). Although the first data at daily scale for this station correspond to 1945 , only from 1973 on the series has at least $75 \%$ of the days in a year represented. For this work, we used daily direction data from the Tarifa station only from 1973 on.

For this work, average monthly temperature and sea level pressure (SLP) have been taken from the NCEP/NCAR 20th Century Reanalysis (v. 2c) covering the 1851-2012 period (Compo et al., 2011). Average monthly precipitation was taken from the Global Precipitation Climatology Centre (v. 7) dataset (Becker et al., 2013) for the period 1901-2013 and at $1^{\mathrm{o}} \times 1^{\mathrm{o}}$ latitude-longitude resolution.

\subsection{Index definition}

In order to characterize the persistence of the easterly winds in the strait of Gibraltar, we selected from ICOADS all the wind direction measurements taken at open sea between the longitudes $8^{\circ}-1^{\circ} \mathrm{W}$ and the latitudes between $32^{\circ}-38^{\circ} \mathrm{N}$ (Fig. 1). In this domain, we computed the so-called easterly wind Directional INdex (EDIN) as the percentage of days per month with prevailing easterly wind. This area was chosen after a calibration procedure aimed to maximize the correlation between the directional index based on ICOADS and an equivalent index computed from observational data at Tarifa for the calibration period 1973-2012. Table I shows the correlation between the EDIN and the calibration series. These correlations range from +0.70 (August, $\mathrm{p}<0.01$ ) to +0.91 (March and December, $\mathrm{p}<0.01$ in both cases) indicating that the index based on ICOADS is highly representative of the changes in wind direction taken by present-day anemometers at the Tarifa site.

Table I. Monthly correlation coefficients between the EDIN and the calibration series. Correlation is statistically significant in all cases at $\mathrm{p}<0.01$.

\begin{tabular}{lllllllllllll}
\hline Annual & Jan & Feb & Mar & Apr & May & Jun & Jul & Aug & Sep & Oct & Nov & Dec \\
\hline 0.85 & 0.89 & 0.86 & 0.91 & 0.90 & 0.82 & 0.76 & 0.72 & 0.70 & 0.82 & 0.90 & 0.84 & 0.91 \\
\hline
\end{tabular}




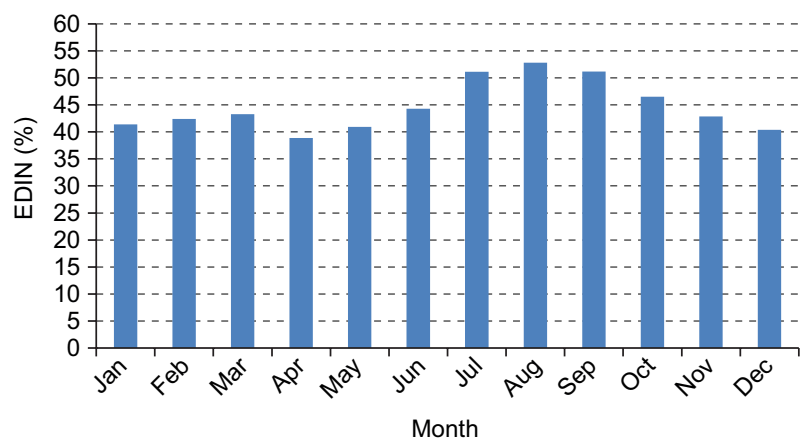

Fig. 2. Monthly averages of the EDIN index (\%) for the period 1850-2014.

\section{Results}

\subsection{EDIN variability}

With the data currently available on ICOADS, it has been possible to compute the EDIN at monthly scale from 1850 to 2014 , although up to the late 1870 s, the series is rather discontinuous. Figure 2 shows the average seasonal march of the index for the period 1850-2014. Levanters are quite frequent along the whole year, with average values around 40 to $50 \%$ for all months. It is in summer when the levanters' frequency is the greatest, with values above $50 \%$ between July and September. During winter, the typical frequency is around 40 to $45 \%$ and the month with less frequency is April.

Figure 3 shows the time evolution of the seasonal EDIN averages. Seasonal series were computed first normalising the monthly values over the base period 1850-2014 and then averaging the normalised monthly values for the corresponding season. Only the cases in which the three months are available have been considered. In general, the easterlies show a large interannual variability and superposed to it, there

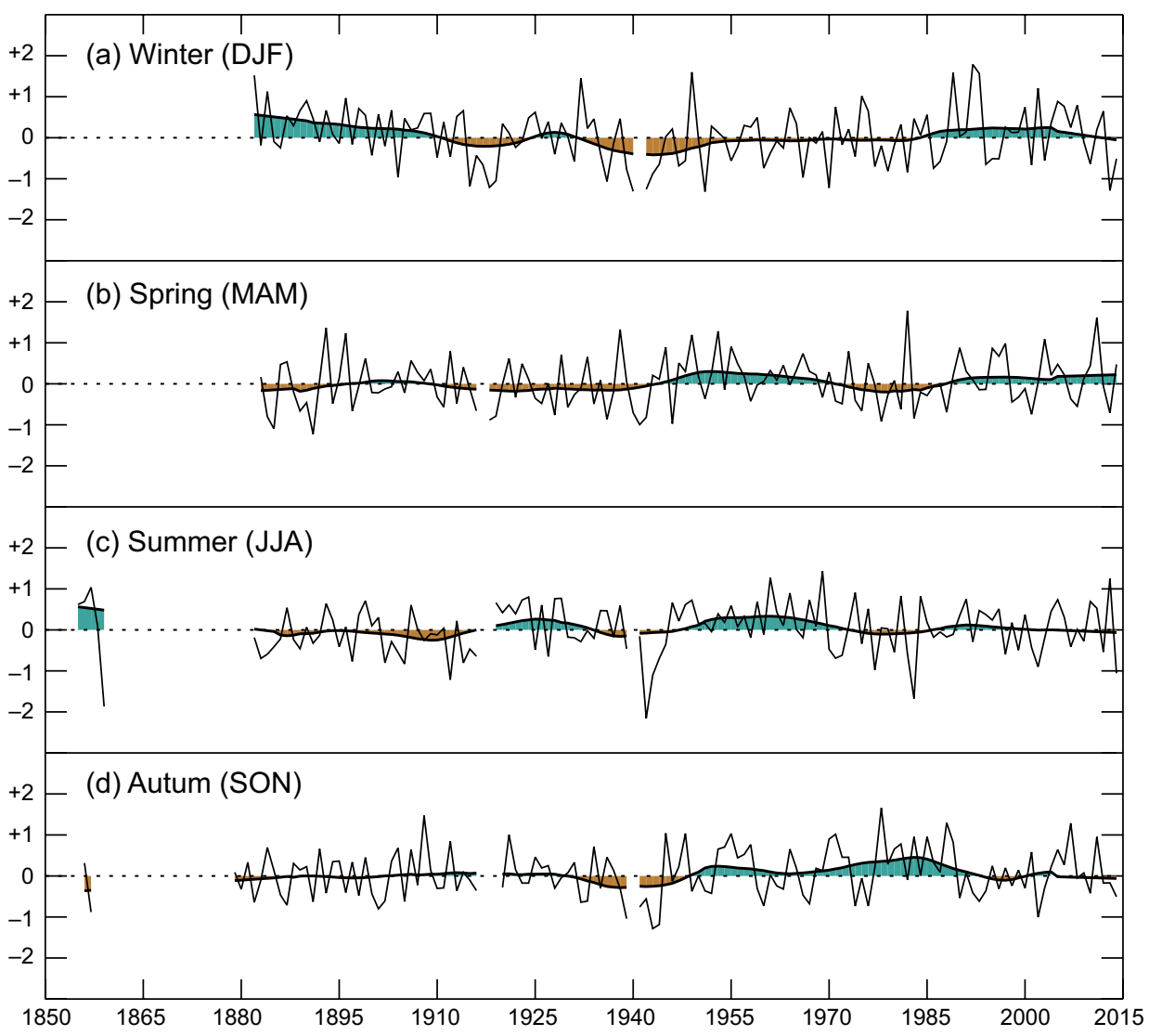

Fig. 3. Normalized EDIN for (a) winter, (b) spring, (c) summer and (d) autumn between 1850 and 2014. The shaded smoothed curve was computed as a robust locally weighted regression with a 21-yr window (Cleveland, 1979). 
is also a noticeable decadal fluctuation. For winter, we found two periods with easterlies more frequent than average (1880-1910 and 1985-2010) and a long interval with predominant lower than average frequencies between 1910 and 1985. For spring, a slow increase of the easterlies frequency is evidenced by the tendency of the EDIN to stay slightly below its low term mean from 1880 to 1940 and above it since that year to the present time (with the exception of a short interval around 1980). For summer, the EDIN shows that the frequency of the easterlies was lower than today during the last two decades of the 19th century and up to 1915. From 1915 and up to 1970 the frequency tended to be mostly above the long-term average. Since 1970, the easterlies have remained more or less stable in summer to the present time. Finally, for autumn, from 1860 until 1930 the easterlies frequency was mainly below the long-term mean and after a 10 -yr period of lower than average values centered at 1940, they have remained predominantly above the average.

A spectral analysis of the seasonal EDIN series has been carried out through the local power spectrum based on a Morlet wavelet (Fig. 4). This methodology makes it possible to determine the dominant modes of variability in a time series along its length (Torrence and Compo, 1998). The large interannual variability of the EDIN evidenced in figure 3 (thin line) is translated as a spectral power concentration around the bands between 2 and 4 yrs for all seasons. However this band is rather discontinuous and only reaches statistical significance for short periods, indicating that the EDIN does not fluctuate at the shorter timescales in a coherent way. On the other hand, the multidecadal variability evidenced by the smoothed EDIN series (shaded curve in Fig. 3) is reflected as a significant oscillation band around $30-40$ yrs in winter from 1910 to the 1950s (Fig. 4a), from 1910 to 1980 in summer (Fig. 4c) and from 1930 to 1990 in autumn (Fig. 4d). Additionally, the autumn series shows a significant oscillatory band around $10 \mathrm{yrs}$ between 1900 and the mid-2000s, which becomes statistically significant from 1940 to the late 1980s.

The long-term fluctuations of the EDIN series revealed in figure 4 strongly suggest a relationship of the EDIN variability to the modes of natural variability of the North Atlantic (Grossmann and Klotzbach, 2009). The three main variability modes identified in

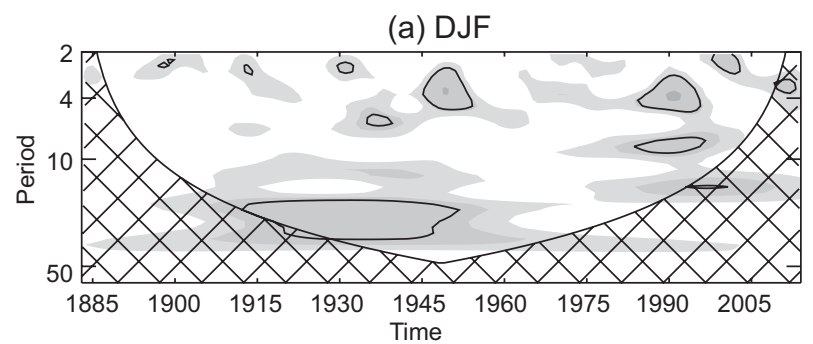

(b) MAM

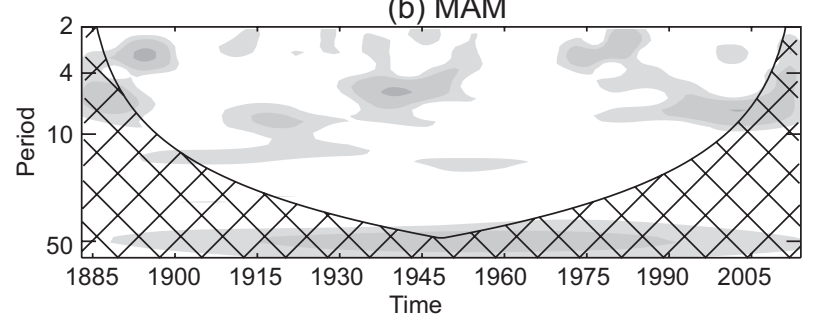

(c) JJA

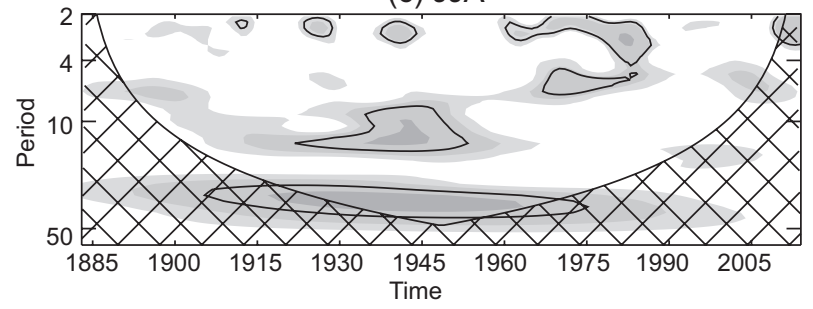

(d) SON

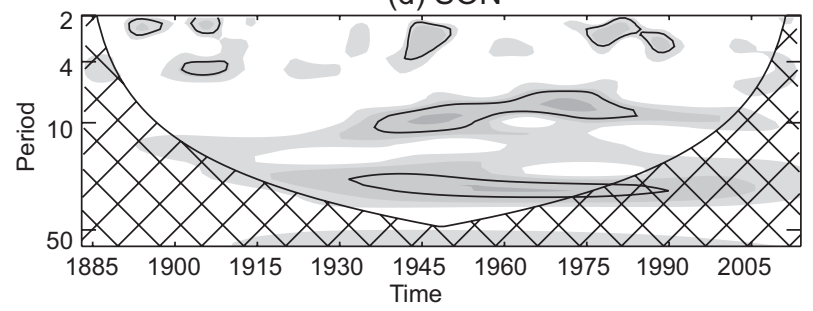

Fig. 4. Wavelet spectrum of the Morlet type of the EDIN seasonal series. Period ( $y$-axis) is indicated in years. Shaded areas indicate the dimensionless power/variance ratio. Cross-hatched areas denote the cone of influence. Solid lines indicate significant oscillation bands at the $\mathrm{p}<0.1$ level.

the North Atlantic are the NAO (Hurrell, 1995), the Atlantic Multidecadal Oscillation (AMO) (Knight et al., 2006; von Gunten et al., 2012) and the Atlantic Meridional Mode (AMM) (Chiang and Vimont, 2004). The NAO can be described as a synchronous variation of the strength of the Icelandic Low and the Azores High. Years of positive NAO phase are characterized by both a stronger than average Azores High and a deeper than average Icelandic Low. This configuration implies an increased north-south pressure gradient and 
strongest westerlies across the Atlantic at mid-latitudes. While the NAO is mainly related to the short term inter-annual variability of the atmosphere in the North Atlantic, the AMO reflects longer-period multidecadal fluctuations of the Atlantic sea surface temperatures (SSTs) (Enfield et al., 2001). During positive (negative) AMO phases, most of the North Atlantic shows warmer (cooler) than long-term average temperatures (warm/cool AMO phases). Although the instrumental AMO index is too short to attain a conclusive determination of the AMO's characteristic frequency, instrumental and proxy evidence indicates that the AMO has significant oscillatory bands between 55 and 70 yrs (Knudsen et al., 2011). Finally, the AMM is a mode of coupled ocean-atmosphere variability in the tropical Atlantic associated with meridional displacements of the intertropical convergence zone (ITCZ) (Camargo et al., 2010). Positive AMM phases are associated to a northward displacement of the Atlantic ITCZ and warmer (cooler) than normal SSTs in the tropical North (South) Atlantic.

In order to analyze the possible relationship of the levanters with these variability modes we performed a running correlation analysis for variable window sizes between 9 and 61 yrs among the EDIN and: (1) the NAO index defined as the pressure difference between Gibraltar and Iceland (Jones et al., 1997) available from 1821 to 2018, (2) the unsmoothed AMO index derived from the Kaplan SST v. 2 dataset between 1856 and 2014 (Enfield et al., 2001), and (3) the SST-based AMM index from Chiang and Vimont (2004), available from 1948 to the present time. Figures 5, 6 and 7 show the results. In all cases, the vertical axis indicates the number of years over which the running correlation was evaluated, while the horizontal axis indicates the center of the window used to compute the running correlation.

The larger correlations are found for the NAO case (Fig. 5). In general, the EDIN-NAO correlations are positive across the year at all timescales, although they are higher for the winter and summer cases (Fig. 5a, c), when it is possible to find periods of significant correlation larger than $+0.6(\mathrm{p}<0.05)$. During the transitional seasons (spring and autumn) the EDIN-NAO correlations are predominantly positive as well (Fig. 5b, d) but they are in general lower. For all cases, it is evident that the EDIN-NAO correlation has not been stable in time, as periods of low or even negative correlations can be found, as for example the 1960s decade for the winter case (Fig. 5a) or the late 1990s and the 1920s for the autumn case (Fig. 5d).

In general, neither the AMO (Fig. 6) nor the AMM (Fig. 7) are significantly correlated with the EDIN at any time scale but for some short intervals. EDINAMO correlations are quite variable, although for some seasons such as autumn (Fig. 6d) they shows a slight tendency to negative values (warmer SSTs in the North Atlantic associated to more frequent levanters), but the values are not statistically significant. Unfortunately, the AMM series is too short to analyze the long-term EDIN-AMM relationship, but the available period (1948-2014) does not show any predominant correlation. Values are mostly alternating in sign, not reaching statistical significance but for some brief periods around the 2000s in winter and summer (Fig. 7a, c).

\subsection{Precipitation and temperature anomalies asso- ciated to the EDIN variability}

The large correlations between the NAO and the EDIN strongly suggest that the levanters are related to the interannual variability of the synoptic-scale atmospheric configuration of the North Atlantic and in consequence, it is foreseeable a strong relation between the levanters and precipitation and temperature anomalies in Europe. To assess the relation between the EDIN and the meteorological fields at continental scale, we considered the normalized EDIN each month and computed the temperature and precipitation differences for the cases of EDIN above/below one standard deviation with respect to the 1901-2012 period. Figure 8 shows the case of the precipitation, with the corresponding SLP anomalies also displayed (lines). In general, high EDIN values (i.e., large levanters frequencies) are related to precipitation deficits in large areas of Southern Europe. This is especially evident in northern Spain and Italy, as well as southern France and the Balkans for the winter months. Larger than average precipitations coincident to high EDIN values can be found over the western coasts of southern Scandinavia from October to March. This anomalous precipitation pattern is consistent with the observed SLP anomalies, which shows anomalous high pressures in Central Europe, evident along the entire year but more intense during autumn and winter. 
(a) DJF

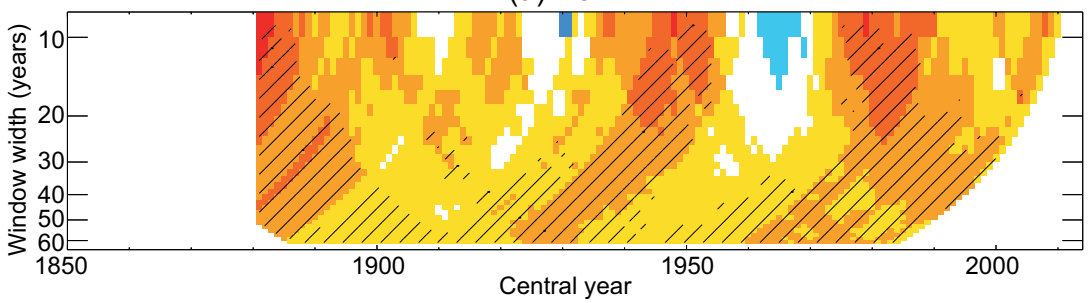

(b) MAM

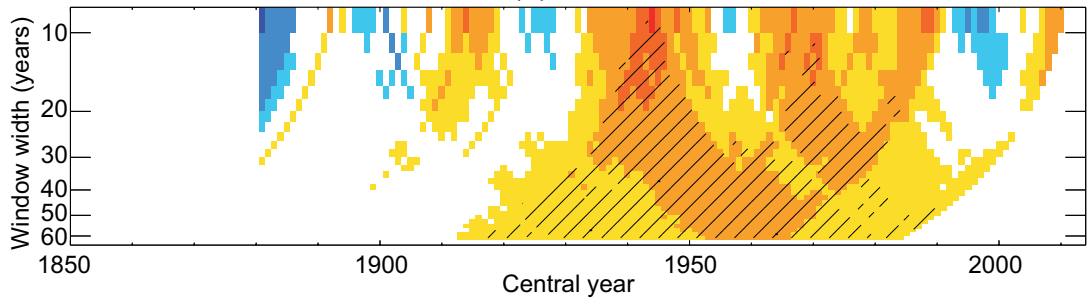

(c) JJA

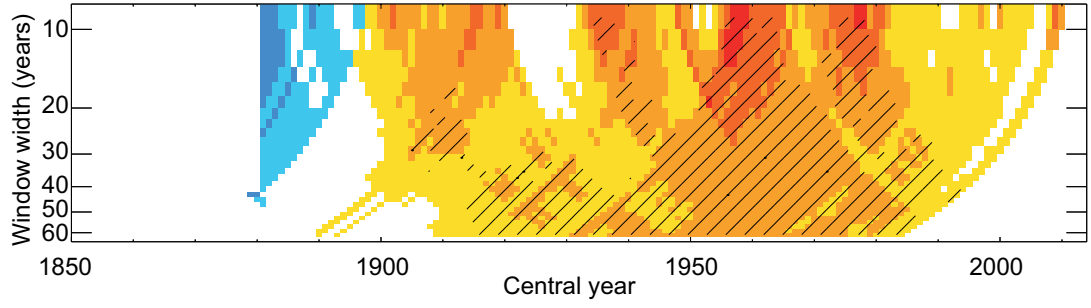

(d) SON
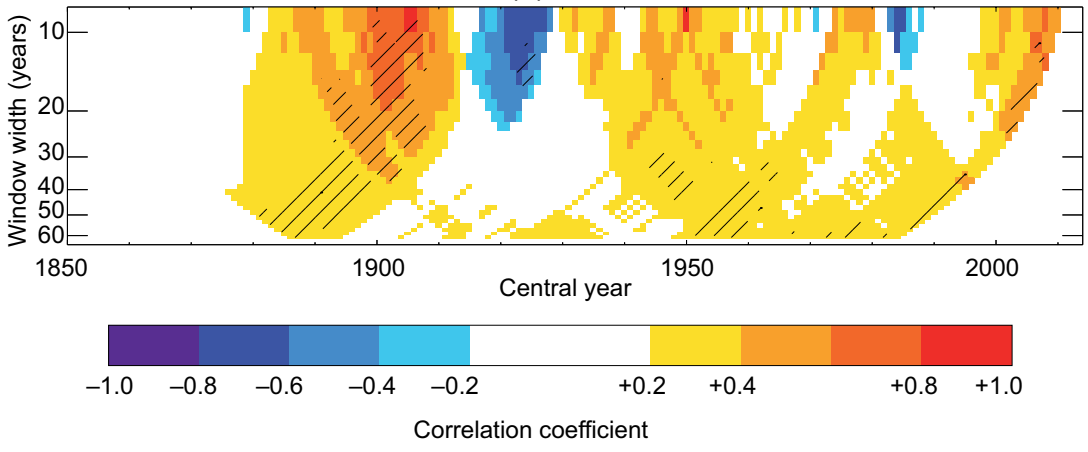

Fig. 5. Running Pearson's correlation coefficient for variable window width (y-axis) between the EDIN and the NAO index for (a) winter, (b) spring, (c) summer and (d) autumn. Hatched areas indicate statistically significant correlations at $\mathrm{p}<0.05 . x$-axis is escalated as in figure 3 to ease comparison.

When this same analysis is performed for the temperature field (Fig. 9) a clear dipolar structure is observed, but its structure is rather dependent on the month. Between December and March, large EDIN values are related to warm/cold anomalies in Northern Europe/Northern Africa and Turkey. This pattern is entirely consistent with the anomalous anticyclonic circulation imposed by the SLP. Be- tween April and October, the SLP anomalies related to the EDIN extremes are significantly lower, as well as the corresponding temperature anomalies. Interestingly, in large areas of southern Spain and Morocco, during these months large frequencies of the easterly winds are related to higher than average temperatures that in some months can reach up to $4{ }^{\circ} \mathrm{C}$. 
(a) DJF

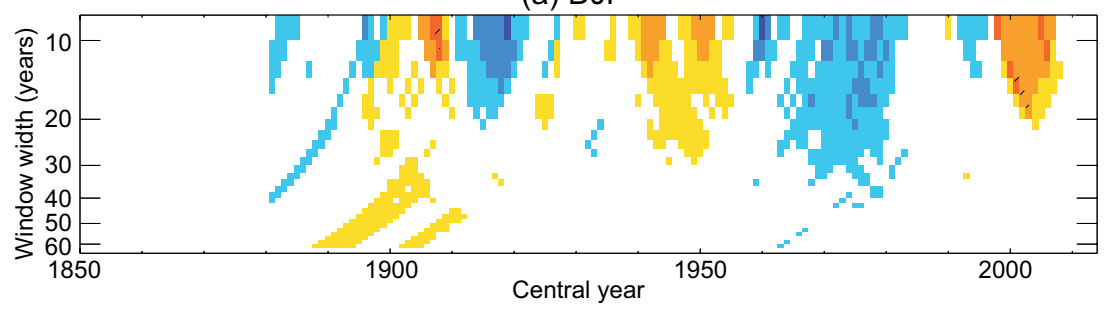

(b) MAM

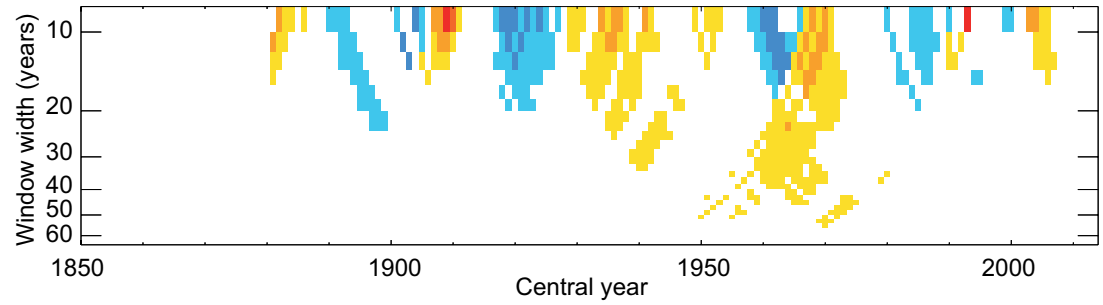

(c) JJA

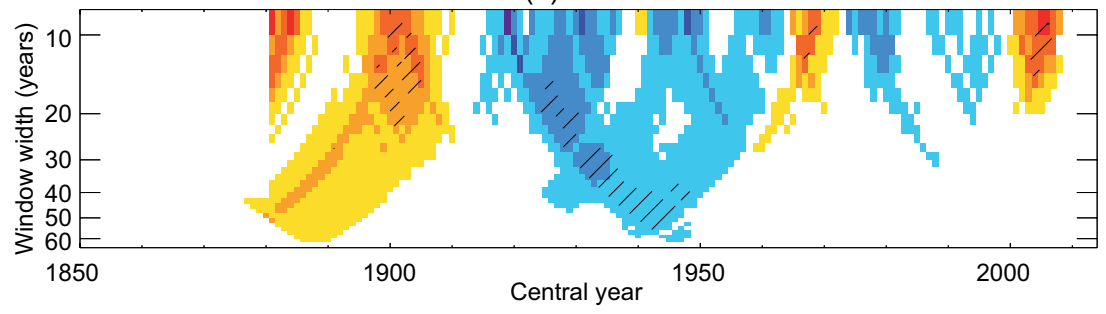

(d) SON

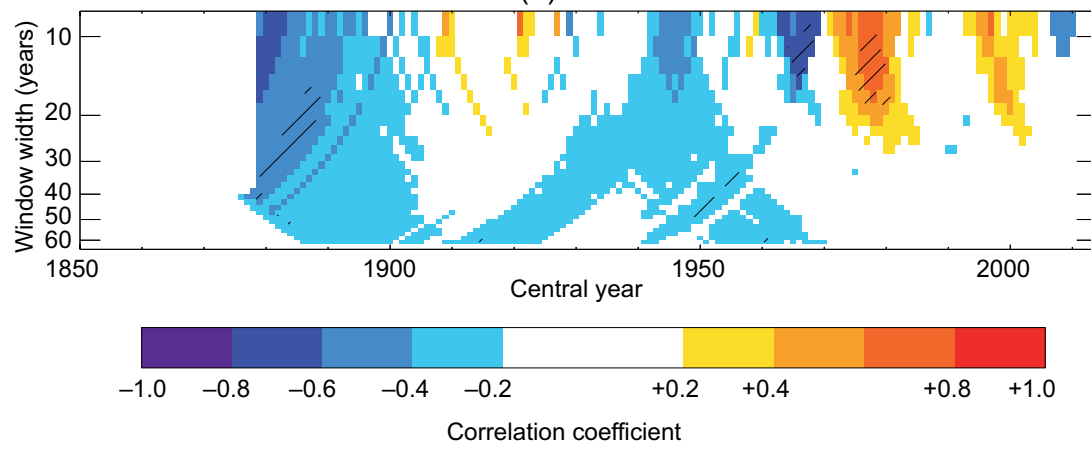

Fig. 6. As in figure 5 but for the AMO index.

\section{Summary and discussion}

In this paper it is presented the first climatology for the levanters in the strait of Gibraltar based on historical wind observations, allowing, for the first time to characterize these winds since the late 19th century. During the last years, a number of indices based on in situ wind direction observations taken aboard ships have been developed. For a recent review, the reader is referred to García-Herrera et al. (2018). The great advantage of these indices lies in the exclusive use of instrumental observations, and this fact constitutes a great advantage over other approaches. In this sense, Vega et al. (2018) revealed that analogous indices computed from reanalysis products could be uncertain for years prior to the mid-20th century. To illustrate this fact, we computed the average zonal wind speed at the near surface level (sigma 0.995) from the 20th Century Reanalysis (20CR) and for the area $\left[32^{\circ}-38^{\circ} \mathrm{N}, 8^{\circ}-1^{\circ} \mathrm{W}\right]$ domain (the same used to define the EDIN) and 
(a) DJF

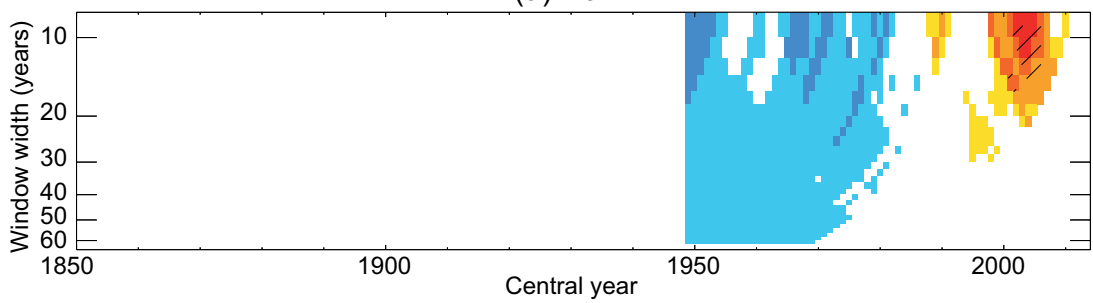

(b) MAM

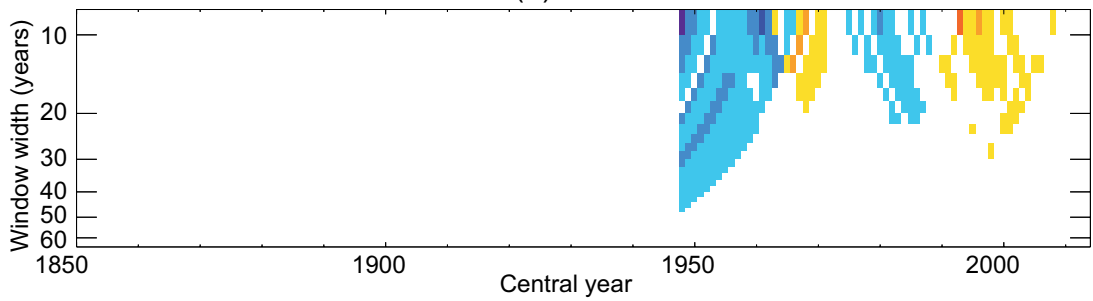

(c) JJA

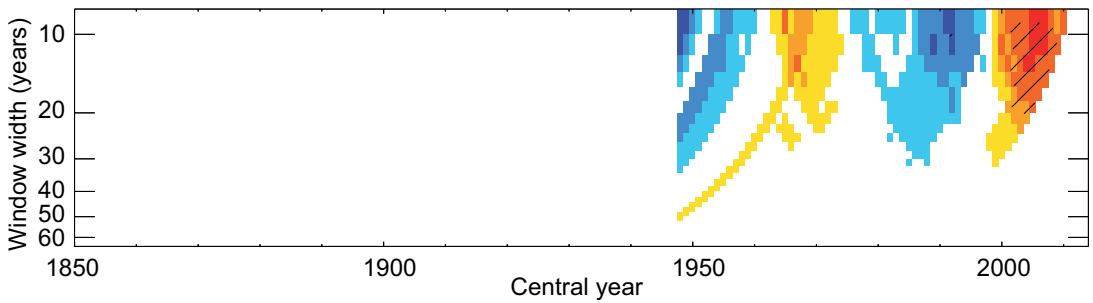

(d) SON

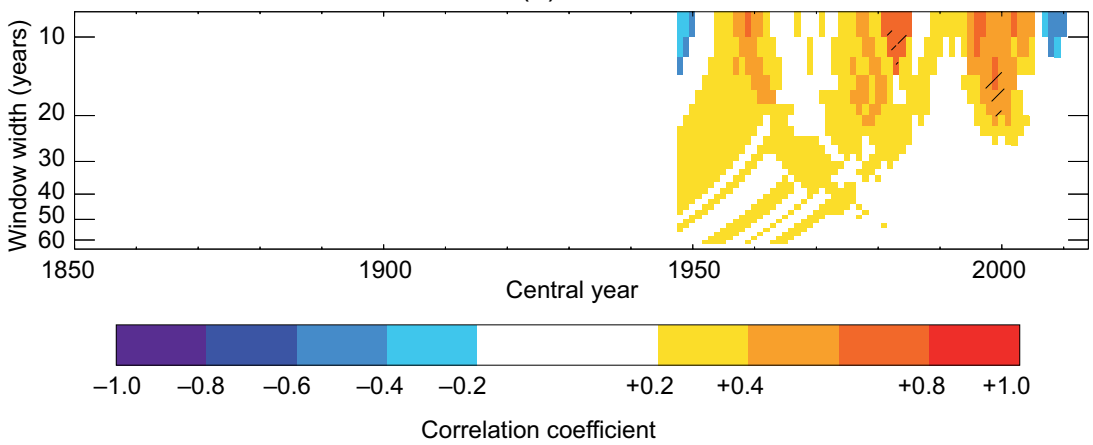

Fig. 7. As in figure 5 but for the AMM index.

then we computed the seasonal running correlations between this average wind and the EDIN (Fig. 10). As expected, correlations are mainly negative (more frequent levanters associated to larger negative zonal winds). Interestingly, for the post 1950s years, the agreement between the variability of the 20CR average zonal wind and the EDIN is excellent, especially during autumn and winter, with stable and significant correlations around $-0.90(\mathrm{p}<0.05)$. However, for years prior to the mid-20th century, the correlations present large drops. This is particularly evident for the winter between 1905 and 1940 (Fig. 8a), but also for the summer and autumn (Fig. 8c, d). In these cases, the correlation even reaches positive values around 1940. Recently, Vega et al (2018) found that during the periods of significantly lower than present-day data coverage in the North Atlantic and the Pacific, indices computed from historical reanalysis can be scarcely representative of local wind circulation. These authors 

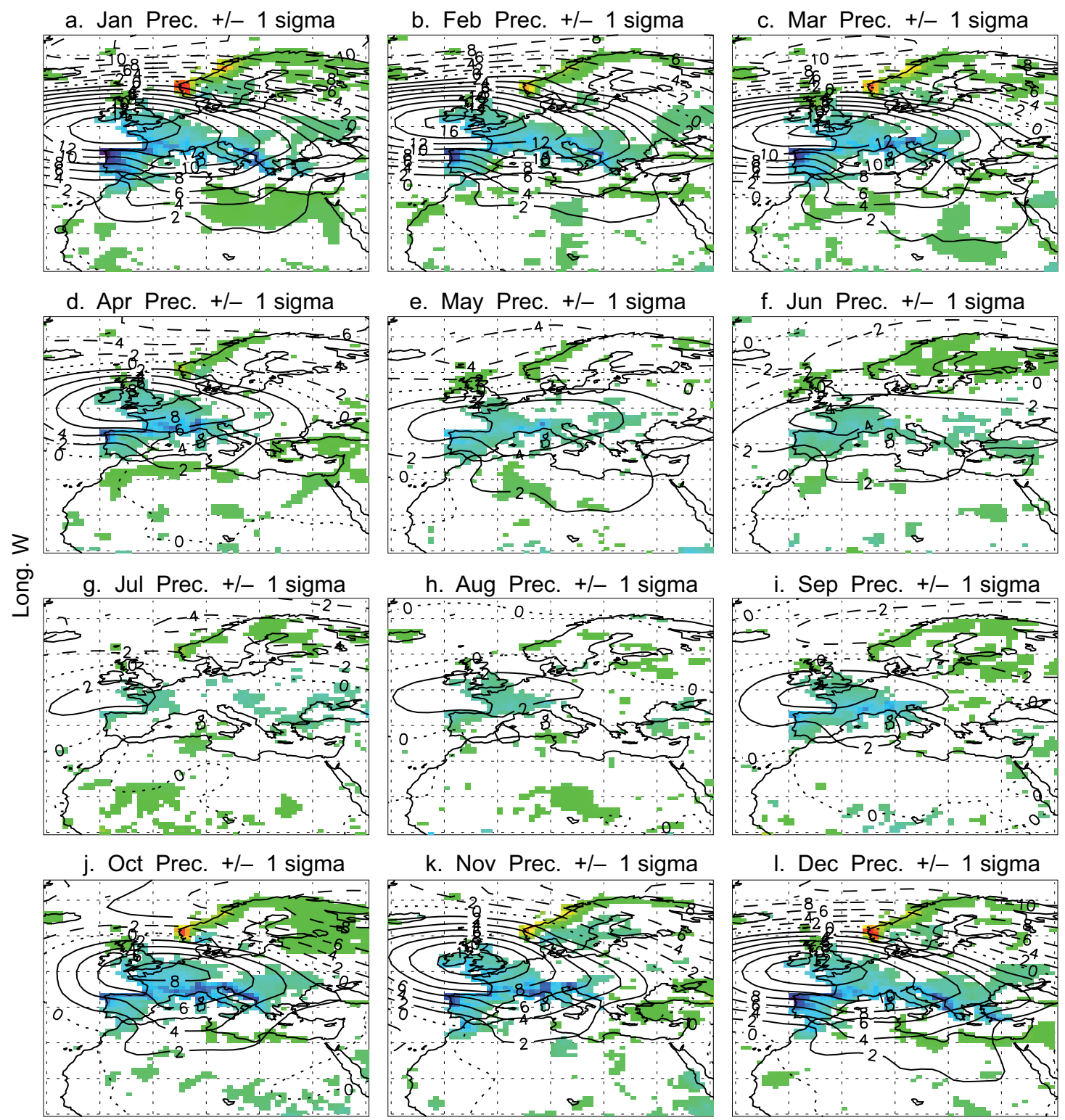

k. Nov Prec. +/- 1 sigma
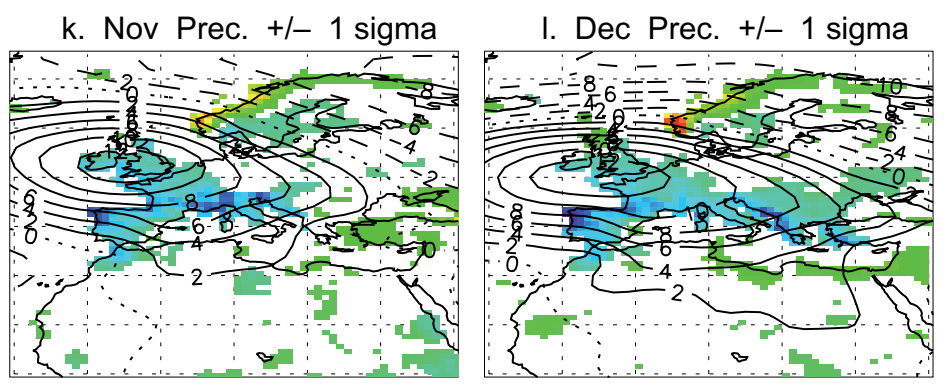

Lat. $\mathrm{N}$

Precipitation anomaly $(\mathrm{mm})$

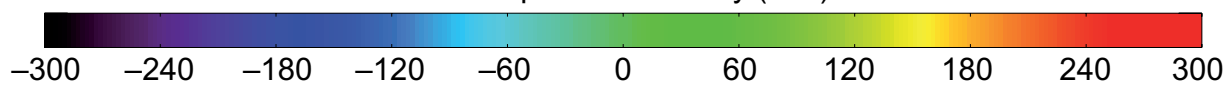

Fig. 8. Precipitation anomalies (shading, $\mathrm{mm}$ ) and corresponding sea level pressure anomalies (lines, hPa) for years with EDIN above/below one standard deviation of its average value for the 1901-2012 period. Only areas with precipitation differences statistically significant at $\mathrm{p}<0.05$ are represented.

found that circulation indices based on different historical reanalysis such as ERA-20C and 20CR usually disagree for years prior to 1950 , and that in these cases, directional indices can be superior in terms of explaining precipitation and temperature anomalies related to anomalous winds. This seems to be the case of the EDIN as our comparison with data, independent of historical reanalysis (as the 
a. Jan Temp. +/- 1 sigma

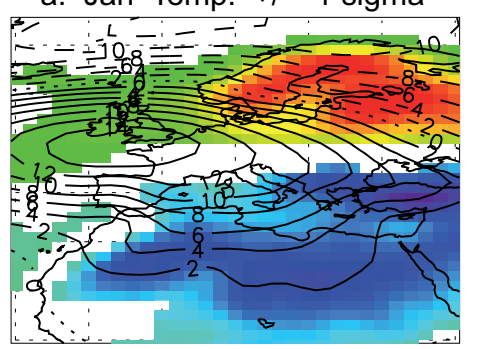

d. Apr Temp. +/- 1 sigma

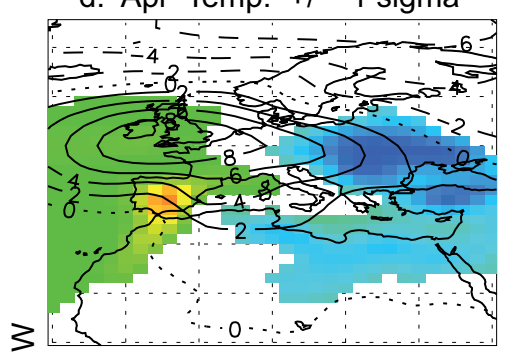

ค่ g. Jul Temp. +/- 1 sigma

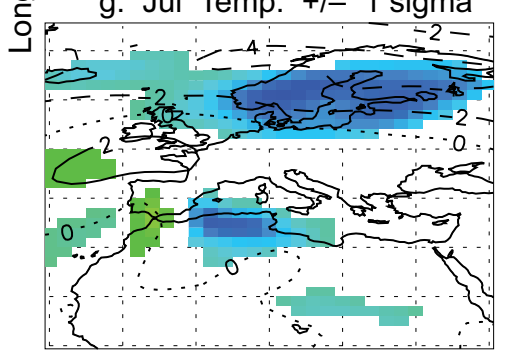

j. Oct Temp. +/- 1 sigma
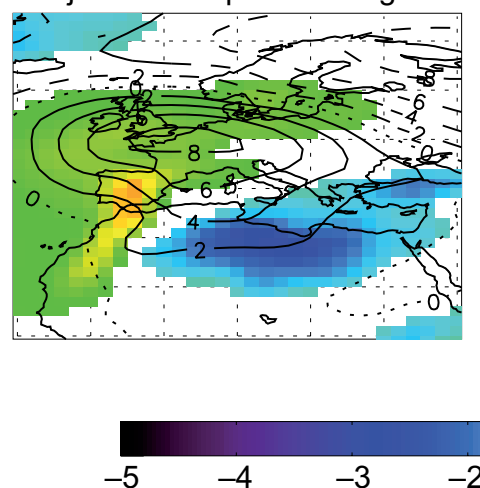

b. Feb Temp. +/- 1 sigma

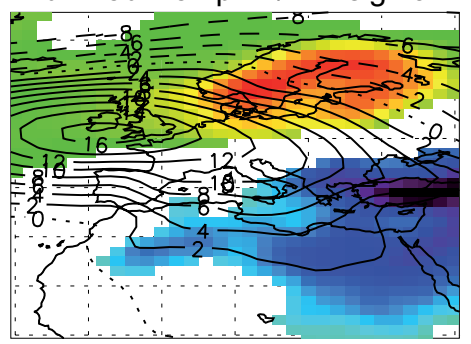

e. May Temp. +/- 1 sigma

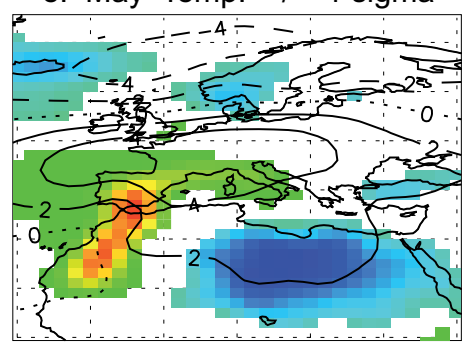

h. Aug Temp. +/- 1 sigma

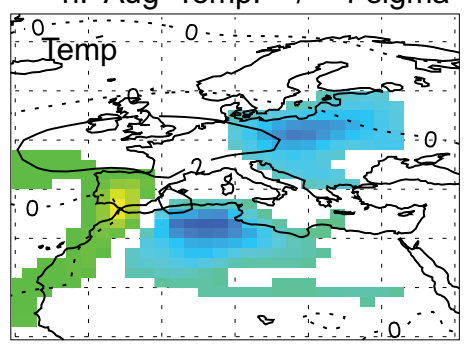

k. Nov Temp. +/- 1 sigma

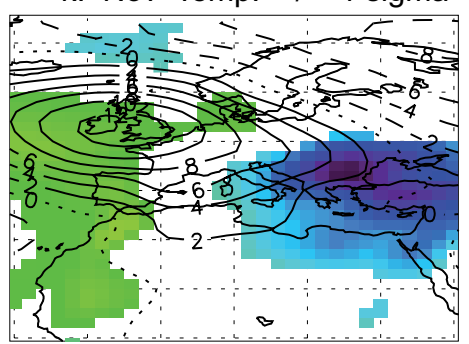

Lat. N

Temperature anomaly (Celsius)

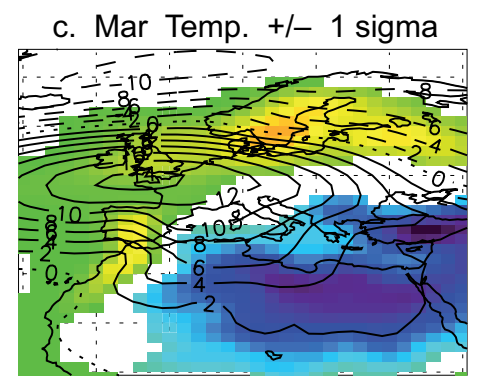

f. Jun Temp. +/- 1 sigma

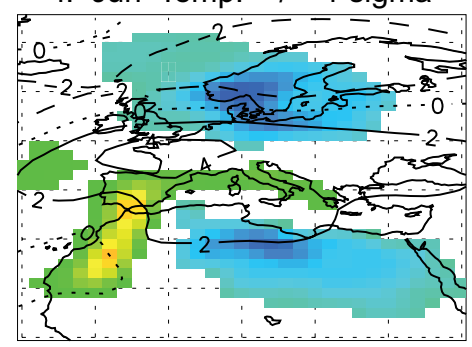

i. Sep Temp. +/- 1 sigma

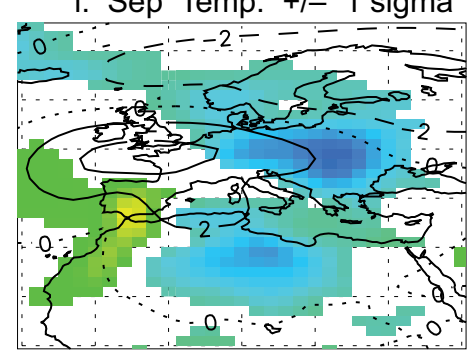

I. Dec Temp. +/- 1 sigma

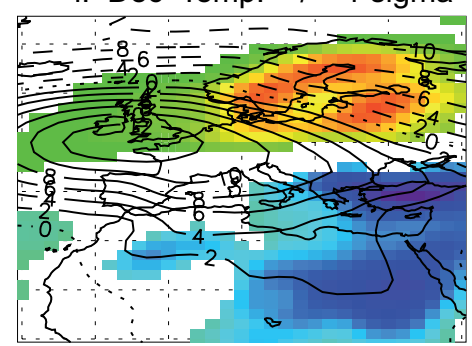

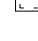

\section{(1)}


(a) DJF

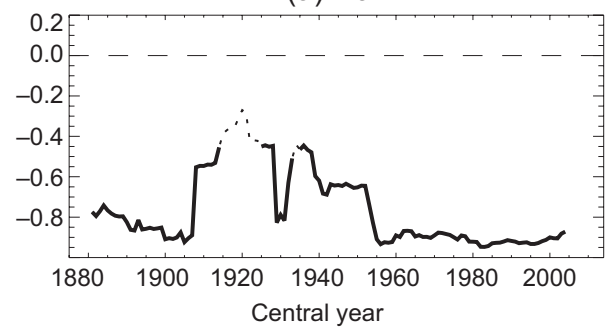

(c) JJA

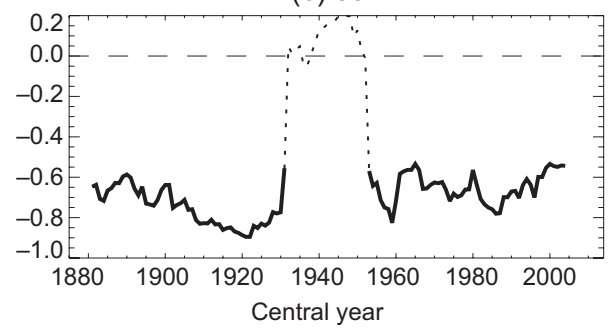

(b) MAM

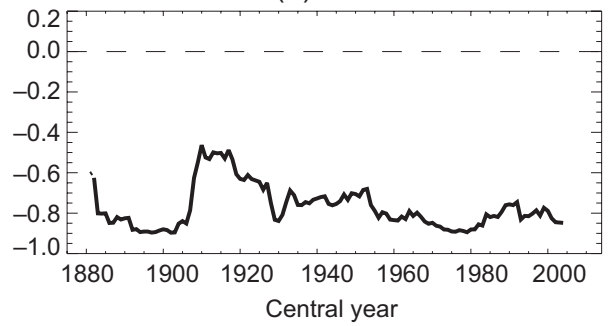

(d) SON

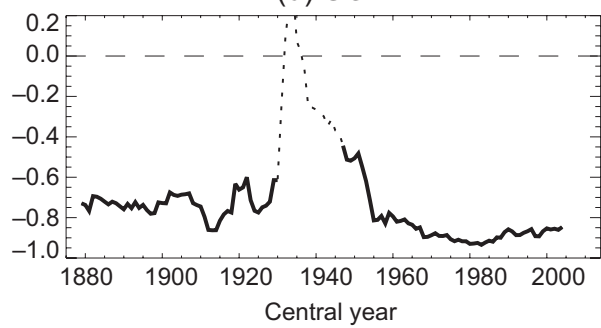

Fig. 10. Seasonal running correlations for a 21-yr window among the EDIN and the 20CR zonal wind speed at the 0.995-sigma level averaged over the same area in which the EDIN is defined. Significant correlations at the $\mathrm{p}<0.05$ level are indicated by a thicker continuous line.

2. The interannual variability of the levanters is rather high. The levanters show a noticeable variability at decadal scales as well. A spectral analysis shows that the frequency of the shorter oscillations (2-4 $\mathrm{yrs})$ is not stable in time. However, there is a noticeable spectral concentration for frequencies around 20 to 40 yrs in winter and 10 to $40 \mathrm{yrs}$ in summer and autumn. The filtered EDIN (Fig. 3) evidences these changes as alternating periods of above/below the long term average typically lasting between 20 and 40 yrs. We have not found statistically significant long-term trends in the levanters frequency, but the evolution of the seasonal EDIN records shows that, between spring and autumn, since the last part of the 19th century and up to approximately 1940, the frequency of the easterlies in the strait of Gibraltar was slightly lower than today and in general, since that decade, their frequency have stayed above the long term average.

3. The NAO is the only large-scale climate variability mode significantly correlated with the EDIN, especially during winter and summer. This correlation is mainly positive but it is not stable in time. In this sense, Barriopedro et al. (2014) demonstrated that this kind of decoupling between a local circulation index such as the EDIN and the NAO index arises from departures of the NAO dipole from zonality. In this way, different SLP configurations (essentially the migration of the NAO's centers of action), which are compatible with a similar value of the NAO index, can result in different wind anomalies far from the centers of action. Therefore, although the NAO is significantly related with the levanters through the modulation of the Azores High, it cannot be used as a reliable predictor of the long-term levanter variability.

4. We did not found significant correlations between the EDIN and the AMO or the AMM. The absence of correlation with the AMO suggests that the long-period oscillations of the EDIN are not related to the long term temperature changes of the North Atlantic. Finally, the absence of correlation with the AMM indicates that the changes in the location of the ITCZ (and the corresponding SST anomalies in the tropical North Atlantic) do not significantly affect the levanters frequency in the strait of Gibraltar. 
5. Due to its dependence on the strength and location of the Azores High, the frequency of the levanters is highly related to precipitation anomalies in large areas of Europe, especially during autumn and winter. In general, larger frequencies imply lower precipitations in northern Spain, Italy, southern France and the Balkans, and greater precipitations in the western coast of Scandinavia. The corresponding SLP anomalies reveal an anomalous center of high pressure up to $12 \mathrm{hPa}$ centered in the British Isles and lower than average SLPs northward of the $60^{\circ} \mathrm{N}$ parallel. This is consistent with the significant link we found between the EDIN and the NAO, as this SLP configuration favors a positive NAO index. However, it must be pointed out that the SLP anomalies associated to extreme EDIN values shown in figures 8 and 9 do not have the canonical structure of the NAO-like SLP dipole (see for example figure 1 in Hurrel, 1995) but rather indicate an increase of the blocking episodes in this area during periods of more frequent levanters. This also explains both the precipitation deficits in Southern Europe and the increases in Scandinavia, since a large number of mid-latitude storms are forced to pass through these northern latitudes during blocking episodes.

6. Interestingly, in average, large frequencies of easterly winds in the strait of Gibraltar do not imply significant negative SLP anomalies over the Sahara. Strong levanters have been classically assumed to be highly favored by the presence of a deep thermal low over the Sahara, but we did not find significant changes in the SLP over the Sahara related to extremes in levanters' occurrence (see Figs. 8 and 9). On the contrary, as indicated in previous paragraphs, the presence of a blocking anticyclone over central Europe appears more relevant for the occurrence of persistent levanters.

7. The large changes in the SLP field associated to the levanters are related to changes in the temperature advection over all Europe and eastern Asia. Because of this, large and significant temperature anomalies over Eurasia appear related to the levanters. In the cold half of the year, large frequencies of levanters are related to warmer/cooler conditions over Northern Europe/Northern Africa and Turkey. During the summer, the lower SLP gradients imply lower and not so organized tem- perature anomalies, but the association between the levanters and warm summer temperatures in southern Spain and Morocco is clearly found. This warm anomaly can reach up to $4^{\circ} \mathrm{C}$ over the average monthly values in July.

As a final remark, it is worth mentioning that the original data used to compute the EDIN were taken from the currently available ICOADS database (3.0 release). We were able to build a reliable circulation index for a relevant area of Southern Europe starting in the late 19th century. Although the levanters variability is significantly related to the NAO, it also displays a distinctive signal independent from the main Atlantic large-scale atmospheric and oceanic variability modes. Because of this, and also because of the profound link of the levanters variability with continental-scale temperature and precipitation anomalies, extending the EDIN series as backwards in time as possible would be extremely interesting. According to Wheeler and García-Herrera (2008) there are still thousands of logbooks in several British archives not yet digitized. It is to be expected that a number of these logbooks contain data from ships sailing from Britain mainland to Gibraltar and the Mediterranean. The direct application of our methodology to these data would probably allow extending the EDIN series back in time up to the late 18th century, improving our knowledge of the long-term wind variability in Southern Europe.

\section{Acknowledgments}

NCEP Reanalysis derived data, CMAP precipitation data and GPCC precipitation data provided by the NOAA/OAR/ESRL PSD, Boulder, Colorado, USA, from their website at http://www.esrl.noaa.gov/psd/. ICOADS data provided by the NCAR/UCAR Research Data Archive, from their website at https://rda. ucar.edu/datasets/ds548.0/. We thank two anonymous reviewers for valuable comments on an earlier draft of this paper. This research was partially funded by Spain's Ministerio de Economía y Competitividad through the project CGL2013-44530-P.

\section{References}

Allan R, Brohan P, Compo GP, Stone R, Luterbacher J, Brönnimann S. 2011. The International Atmospheric 
Circulation Reconstructions over the Earth (ACRE) Initiative. Bulletin of the American Meteorological Society 92:1421-1425. DOI: 10.1175/2011BAMS3218.1

Barriopedro D, Gallego D, Álvarez-Castro MC, García-Herrera R, Wheeler D, Peña-Ortiz C, Barbosa SM. 2014. Witnessing North Atlantic westerlies variability from ship's logbooks (1685-2008). Climate Dynamics 43:939-955.

DOI: $10.1007 / \mathrm{s} 00382-013-1957-8$

Becker A, Finger P, Meyer-Christoffer A, Rudolf B, Schamm K, Schneider U, Ziese M. 2013. A description of the global land-surface precipitation data products of the Global Precipitation Climatology Centre with sample applications including centennial (trend) analysis from 1901-present. Earth System Science Data 5:71-99. DOI: 10.5194/essd-5-71-2013

Camargo S, Sobel A, Barnston A, Klotzbach P. 2010. The influence of natural climate variability, and seasonal forecasts of tropical cyclone activity. In Chan JCL, Kepert JD, eds. Global perspectives on tropical cyclones. Singapore: World Scientific Publishing, 325360. DOI: 10.1142/9789814293488_0010.

Capon RA. 2006. High resolution studies of the Gibraltar Levanter validated using sun-glint anemometry. $\mathrm{Me}$ teorological Applications 13:257-265.

DOI: $10.1017 / \mathrm{S} 135048270600226 \mathrm{X}$

Chiang JCH, Vimont DJ. 2004. Analogous meridional modes of atmosphere-ocean variability in the tropical Pacific and tropical Atlantic. Journal of Climate 17, 4143-4158.

DOI: $10.1175 /$ JCLI4953.1

Cleveland WS. 1979. Robust locally weighted regression and smoothing scatterplots. Journal of the American Statistical Association 74:829-836.

DOI: $10.1080 / 01621459.1979 .10481038$

Compo GP, Whitaker JS, Sardeshmukh PD, Matsui N, Allan RJ, Yin X, Gleason BE, Vose RS, Rutledge G, Bessemoulin P, Brönnimann S, Brunet M, Crouthamel RI, Grant AN, Groisman PY, Jones PD, Kruk M, Kruger AC, Marshall GJ, Maugeri M, Mok HY, Nordli Ø, Ross TF, Trigo RM, Wang XL, Woodruff SD, Worley SJ. 2011. The Twentieth Century Reanalysis Project. Quarterly Journal of the Royal Meteorological Society 137:1-28. DOI:10.1002/qj.776

Del Río L, Plomaritis TA, Benavente J, Valladares M, Ribera P. 2012. Establishing storm thresholds for the Spanish gulf of Cádiz coast. Geomorphology 143:1323. DOI: 10.1016/j.geomorph.2011.04.048
Dorman CE, Beardsley RC, Limeburner R. 1995. Winds in the strait of Gibraltar. Quarterly Journal of the Royal Meteorological Society 121:1903-1921.

DOI:10.1002/qj.49712152807

Enfield DB, Mestas-Núñez AM, Trimble PJ. 2001. The Atlantic Multidecadal Oscillation and its relationship to rainfall and river flows in the continental U.S. Geophysical Research Letters 28:2077-2080.

DOI: 10.1029/2000GL012745

Fernández JA. 1992. La situación de Levante en el Estrecho. Anales de Geografía de la Universidad Complutense 12:177-181.

Freeman E, Woodruff SD, Worley SJ, Lubker SJ, Kent EC, Angel WE, Berry DI, Brohan P, Eastman R, Gates L, Gloeden W, Ji Z, Lawrimore J, Rayner NA, Rosenhagen G, Smith SR. 2017. ICOADS release 3.0: A major update to the historical marine climate record. International Journal of Climatology 37:2211-2237. DOI: $10.1002 /$ joc. 4775

Gallego D, García-Herrera R, Calvo N, Ribera P. 2007. A new meteorological record for Cádiz (Spain) 18061852: Implications for climatic reconstructions. Journal of Geophysical Research: Atmospheres 112:D12108.

DOI: 10.1029/2007JD008517

Gallego D, Ordóñez P, Ribera P, Peña-Ortiz C, García-Herrera R. 2015. An instrumental index of the West African Monsoon back to the 19th century. Quarterly Journal of the Royal Meteorological Society 141:3166-3176. DOI: 10.1002/qj.2601

García-Herrera R, Können GP, Wheeler D, Prieto MR, Jones PD, Koek FB. 2005. CLIWOC: a climatological database for the World's Oceans 1750-1854. Climatic Change 73:1-12.

DOI: $10.1007 / \mathrm{s} 10584-005-6952-6$

García-Herrera R, Barriopedro D, Gallego D, Mellado-Cano J, Wheeler D, Wilkinson C. 2018. Understanding weather and climate of the last 300 years from ship's logbooks. Wiley Interdisciplinary Reviews; Climate Change 9:e544. DOI: 10.1002/wcc.544

Grossmann I, Klotzbach PJ. 2009. A review of North Atlantic modes of natural variability and their driving mechanisms. Journal of Geophysical Research: Atmospheres 114.

DOI: 10.1029/2009JD012728

Hurrell JW. 1995. Decadal trends in the North Atlantic Oscillation: Regional temperatures and Precipitation. Science 269:676-679.

DOI: $10.1126 /$ science. 269.5224 .676 
Jones PD, Jónsson T, Wheeler D. 1997. Extension to the North Atlantic Oscillation using early instrumental pressure observations from Gibraltar and South-West Iceland. International Journal of Climatology 17:1433-1450. DOI: 10.1002/(SICI)1097-0088(19971115)17: 13<1433::AID-JOC203>3.0.CO;2-P

Knight JR, Folland CK, Scaife AA. 2006. Climate impacts of the Atlantic Multidecadal Oscillation. Geophysical Research Letters 33:L17706.

DOI: 10.1029/2006GL026242

Knudsen MF, Seidenkrantz MS, Jacobsen BH, Kuijpers A. 2011. Tracking the Atlantic Multidecadal Oscillation through the last 8,000 years. Nature Communications 2:178. DOI: $10.1038 /$ ncomms 1186

Ordóñez P, Gallego D, Ribera P, Peña-Ortiz C, García-Herrera R. 2016. Tracking the Indian Summer Monsoon onset back to the pre-instrumental period. Journal of Climate 29:8115-8127.

DOI: 10.1175/JCLI-D-15-0788.1

Prieto MR, Gallego D, García-Herrera R, Calvo N. 2005. Deriving wind force terms from nautical reports through content analysis. The Spanish and French cases. Climatic Change 73:37-55. DOI: 10.1007/s10584-005-6956-2

Stepek A, Wijnant IL, van der Schrier G, van den Besselaar EJM, Klein Tank AMG. 2012. Severe wind gust thresholds for Meteoalarm derived from uniform return periods in ECA\&D. Natural Hazards and Earth System Sciences 12:1969-1981.

DOI: $10.5194 /$ nhess-12-1969-2012

Torrence C, Compo GP. 1998. A practical guide to wavelet analysis. Bulletin of the American Meteorological Society 79:62-78.

DOI: 10.1175/1520-0477(1998)079<0061:APGTWA $>2.0 . \mathrm{CO} ; 2$

Vega I, Gallego D, Ribera P, Gómez-Delgado FDP, García-Herrera R, Peña-Ortiz C. 2018. Reconstructing the Western North Pacific Summer Monsoon since the late 19th century. Journal of Climate 31:355-368. DOI: 10.1175/JCLI-D-17-0336.1

Von Gunten L, D’Andrea WJ, Bradley RS, Huang Y. 2012. Proxy-to-proxy calibration: increasing the temporal resolution of quantitative climate reconstructions. Scientific Reports 2:609. DOI: 10.1038/srep00609

Wheeler D, García-Herrera R. 2008. Ships' logbooks in climatological research. Annals of the New York Academy of Sciences 1146:1-15.

DOI: 10.1196/annals.1446.006

Wilkinson C, Woodruff SD, Brohan P, Claesson S, Freeman E, Koek F, Lubker SJ, Marzin C, Wheeler D. 2011. Recovery of logbooks and international marine data: the RECLAIM project. International Journal of Climatology 31:968-979.

DOI: $10.1002 /$ joc. 2102 